\title{
FILOSOFI JAWA NRIMO DITINJAU DARI SILA KETUHANAN YANG MAHA ESA
}

\author{
Nisa A'rafiyah Tri Wulandari \\ Program Studi Magister Pendidikan Pancasila dan Kewarganegaraan \\ Universitas Negeri Malang Jl. Semarang No.5 Malang \\ email:niisa.120992@gmail.com
}

\begin{abstract}
Indonesia have local wisdom as reflection of values and characters which is followed by their community. Particularly in Javanese people, life philosophy as local wisdom has so many varieties. One of them is nrimo philosophy. Nrimo is believed as character of Javanese people for living in the world. Javanese people believe that after working hard, nrimo is what should to do (to be grateful for they have done whatever the result are given by God). On this paper, author will describe (1) the concept of Javanese nrimo philosophy, (2) the values contained in nrimo philosophy, and (3) Javenese nrimo philosophy related to first principle of Pancasila, Belief in the one and only God.
\end{abstract}

Key Words: Java society, local wisdom, nrimo, Belief in the one and only God

\begin{abstract}
Abstrak: setiap masyarakat Indonesia memiliki kearifan lokal sebagai cerminan dari nilai dan karakter yang dianut oleh masyarakat itu. Pada masyarakat Jawa khususnya, kearifan lokal yang berupa filosofi hidup banyak sekali ragamnya. Salah satu filosofi hidup yang diyakini oleh mayarakat Jawa adalah nrimo. Nrimo, diyakini sebagai karakter masyarakat Jawa dalam menjalani hidup. Masyarakat Jawa yakin bahwa setelah bekerja keras maka hal yang dilakukan adalah nrimo apapun hasil yang diberikan oleh Tuhan dan bersyukur atas berkah yang telah diberikan oleh Tuhan atas kerja keras yang telah dilakukan. Pada tulisan ini, penulis akan menguraikan (1) konsep filosofi Jawa nrimo, (2) nilai-nilai yang terkandung dalam filosofi nrimo, dan (3) filosofi Jawa nrimo ditinjau dari sila pertama Pancasila, Ketuhanan Yang Maha Esa.
\end{abstract}

Kata Kunci: masyarakat Jawa, kearifan lokal, nrimo, Ketuhanan Yang Maha Esa

Kearifan lokal adalah buah kebijaksanaan dalam suatu masyarakat yang didapat dari interaksi masyarakat dengan lingkungan (baik fisik maupun non fisik) sebagai rasa syukur terhadap karunia Tuhan Yang Maha Esa. Kearifan lokal adalah halhal yang lebih bersifat moral daripada material. Pengertian ini didasarkan pada tulisan Roikhwanphut Mungmachon (2012: 176) yang menyatakan bahwa kearifan lokal merupakan dasar pengetahuan yang didapat dari keseimbangan hidup dengan alam. Pengetahuanpengetahuan dasar tersebut diakumulasikan dalam suatu kebudayaan masyarakat dan tetap dilestarikan dari waktu ke waktu. Kearifan lokal ini dapat berupa sesuatu hal yang abstrak maupun yang kongkret, namun yang jelas baik kearifan lokal yang abstrak maupun kongkret memiliki ciri khas yang sangat penting yaitu keduanya bersumber dari pengalaman atau kebenaran hidup. Sumber kearifan lokal berasal dari pengalaman nyata integrasi antara manusia, spirit, dan lingkungan. Kearifan lokal menekankan pada penghormatan kepada para leluhur dan pengalaman hidup serta menganggap bahwa moral lebih bernilai daripada hal-hal yang bersifat material.

Hampir sama dengan pernyataan di atas, Berker (dalam Dahliani, 2015: 158) menjelaskan bahwa kata kearifan lokal memiliki arti sebagai kumpulan dari pengetahuan, tata kelakuan serta kepercayaan yang merupakan hasil dari proses adaptasi kebudayaan yang berjalan dari generasi ke generasi, yang diasosiasikan dengan hubungan antara makhluk hidup dengan lingkungan. 
Pengetahuan tradisional tentang hubungan antara manusia dan lingkungan (ekologi) dimiliki secara kolektif dan dapat disampaikan melalui berbagai bentuk seperti cerita-cerita rakyat, lagu-lagu, nilainilai budaya, kepercayaan, ritual-ritual, hukum adat, bahasa daerah, dan pemanfaatan sumber daya alam. Jadi, kearifan lokal merupakan wujud dari pengalaman hidup masyarakat yang menyeimbangkan kehidupan manusia dengan alam.

Berdasarkan pernyataan-pernyataan di atas, dapat diketahui bahwa kearifan lokal dapat berwujud sesuatu hal yang kongkret (seperti artefak, ritual/kegiatan, lagu, cerita dan lain sebagainya) maupun abstrak (seperti ide, keyakinan, mitos da lain sebagainya) yang digali dari pengalaman hidup suatu masyarakat. Jadi, dapat disimpulkan bahwa setiap masyarakat akan memiliki kearifan lokal yang berbeda, bergantung pada pengalaman hidup yang dijalani dalam masyarakat tersebut. Pengamalan hidup inilah yang kemudian menjadi salah satu penyebab beragamnya budaya di Indonesia. Budaya-budaya yang tetap dilestarikan dan masih ada sampai sekarang itulah yang disebut kearifan lokal. Sesuai dengan istilah kearifan lokal, budaya-budaya yang ada dalam masyarakat Indonesia mengandung nilai-nilai kebijaksanaan yang dapat digunakan sebagai pedoman dalam berhidupkebangsaan atau dengan kata lain digunakan sebagai alat pemersatu bangsa. Karena meskipun wujud budayanya berbeda tetapi muatan nilainya adalah sejalan, seperti nilai religius, nilai toleransi, nilai peduli sosial dan nilai-nilai lainnya.

Pada masyarakat Jawa terdapat banyak kearifan lokal yang masih dilestarikan sampai saat ini. Kearifan lokal pada masyarakat Jawa berupa ritual-ritual (seperti kenduri mitoni, kenduri puputan, kenduri selapanan, kenduri suronan, kenduri munggahan dan sebagainya(Gesta Bayuadhy, 2015, 18-19)), benda-benda keramat (seperti keris, punden, pohon, sumber air dan sebagainya), cerita-cerita (seperti mitos, wayang, legenda, dan sebagainya), filosofi hidup dan lain sebagainya. Berkaitan dengan filosofi hidup, banyak sesanti yang dijadikan sebagai pegangan dalam hidup. Dalam Kamus Besar Bahasa Indonesia sesanti diartikan sebagai wejangan atau nasehat. Jadi, sesanti yang dalam filosofi Jawa merupakan bentuk dari nasehat dari orang-orang terdahulu dalam menjalani kehidupan. Beberapa sesanti yang sampai saat ini tetap diuri-uri oleh masyarakat Jawa adalah alon-alon waton kelakon(artinya dalam menjalani hidup itu harus pelan tetapi pasti, tidak grusah-grusuh atau gegabah); ojo gumunan, ojo getunan, ojokagetan, ojo aleman (artinya jangan mudah heran, mudah menyesal, mudah kaget, dan manja); sopo nandur, bakalan ngunduh (artinya setiap hal yang dilakukan akan kembali pada diri sendiri); urip iku urup (artinya hidup itu isinya adalah berusaha berbuat baik sehingga membuat dunia menjadi terang; ojo kuminter mundhal keblinger, ojo cidra mundhak cilok(artinya dalam hidup itu janganlah mengagungkan diri sendiri dan meremehkan orang lain karena akan membuat diri menjadi celaka); ngluruk tanpa bala, menang tanpa ngasorake, sekti tanpa aji-aji, sugih tanpa bandha(artinya menjalani hidup itu harus rendah hati); dan lain sebagainya.

Dengan adanya berbagai filosofi hidup yang memberikan tuntunan dalam berucap, bertindak, dan berperilaku maka tidak heran ketika hasil penelitian yang dilakukan oleh New Economics Foundation (NEF) London tentang the Happy Planet Index (HPI) pada 151 negara di dunia, Indonesia menempati urutan ke 14 sebagai happiest countries on the planet setelah Negara Costa Rica, Vietnam, Colombia, Belize, El Salvador, Jamaica, Panama, Nicaragua, Venezuela, Guatemala, Bangladesh, Cuba, dan Honduras (CNN, 2012). Berdasarkan hasil penelitian di atas, memberikan pengertian bahwa filosofi hidup yang dianut oleh masyarakat Jawa pada khususnya dan masyarakat Indonesia pada umumnya mengantarkan masyarakat Indonesia menjadi masyarakat yang berbahagia dalam mengadapi berbagai tantangan dan masalah kehidupan. Karena adanya keyakinan kuat bahwa ada yang telah mengatur hidup maka hidup orang Indonesia itu tansahalon-alon waton kelakon.

Berkaitan dengan filosofi hidup yang diyakini oleh masyarakat Jawa, ada salah satu filosofi hidup yang tertarik untuk penulis telaah secara kritis, yaitu filofofi hidup nrimo. Filosofi hidup nrimo popular di dalam kehidupan masyarkat Jawa dalam sesanti nrimo ing pandum, makaryo ing nyoto. Dua kalimat pada sesanti ini merupakan satu kesatuan yang tidak boleh dipisahkan karena akan mempengaruhi arti serta makna aslinya sehingga menjadikan salah kaprah. Berdasarkan hal tersebut, pada bagian selanjutnya penulis akan menguraikan makna dan nilai-nilai yang terkandung dalam filosofi Jawa nrimo dan filosofi Jawa nrimo 
ditelaah dari Sila Pertama Pancasila, Ketuhanan Yang Maha Esa.

\section{MAKNA DAN NILAI-NILAI YANG TERKANDUNG DALAM FILOSOFI JAWA NRIMO}

Pada tahun 2010, jumlah penduduk Indonesia adalah sebanyak 237.641.326 jiwa dan 57,5 persen penduduk tinggal di Pulau Jawa (BPS, 2010). Berdasarkan hasil sensus tersebut diketahui bahwa sebagian besar penduduk Indonesia tinggal di Pulau Jawa. Penduduk yang tinggal di Pulau Jawa terdiri dari beberapa suku bangsa yaitu Suku Jawa, Suku Sunda, Suku Madura, dan suku-suku lain yang berasal dari luar Pulau Jawa seperti Suku Batak, Suku Minahasa, keturunan bangsa Asing seperti Cina, Arab, Belanda dan lain sebagainya. Dari berbagai suku yang ada di Indonesia, sekitar 40.2 persen (sebanyak 95.2 juta jiwa) berasal dari suku Jawa baik yang tinggal di Pulau Jawa maupun diluar Pulau Jawa yang merupakan gabungan dari Suku Jawa, Osing, Tengger, Samin, Bawean/Boyan, Naga, dan Nagaring (BPS, 2011). Cipta, rasa, dan karsa yang dihasilkan oleh Suku Jawa inilah yang menghasilkan kebudayaan Jawa. Sebagaimana yang disebutkan oleh Kamajaya (dalam Wibawa Sutrisna, 2013), kebudayaan Jawa adalah pancaran atau pangejawantahan budi manusia Jawa, yang merangkum kemauan, cita-cita, ide, maupun semangatnya dalam mencapai kesejahteraan, keselamatan, dan kebahagiaan lahir batin. Salah satu bentuk pengejahwantahannya tertuang dalam filosofi hidup masyarakat Jawa, yang dikenal dengan istilah filosofi Jawa. Menurut Wibawa Sutrisna (2013), Filsafat Jawa juga dapat dikatakan ngudi kasampurnan (berusaha mencari kesempurnaan). Pendapatnya ini didasarkan pendapat Ciptoprawiro yang menyatakan bahwa ungkapan-ungkapan renungan-renungan filsafat Jawa merupakan sarana untuk mencapai kesempurnaan, suatu langkah ke jalan menuju kelepasan atau bahkan mencapainya, satu-satunya jalan bagi manusia untuk sampai kepada tujuan akhirnya. Lebih lanjut Kusbandrijo (dalam Wibawa Sutrisna, 2013) menjabarkan bahwa Filsafat Jawa dipengaruhi oleh Filsafat India dan Cina, yang kemudian konsep-konsep dari India dan Cina tersebut diubah dan disesuaikan dengan ajaran Islam. Seperti halnya Filsafat India, Filsafat Jawa juga menekankan pada kesempurnaan hidup. Kesempurnaan hidup masyarakat Jawa sangat berkaitan dengan hakekat manusia sebagai makhluk Tuhan, manusia yang selalu berfikir dan merenungi kehidupannya dalam mencapai integritas dirinya dengan Tuhan. Kehidupan yang sarat dengan upaya untu mengintegrasikan dirinya sebagai makhluk Tuhan inilah yang merupakan karakteristik masyarakat Jawa yang dominan dan tidak dapat dipisahkan. Dengan demikian, pencapaian kesempurnaan hidup merupakan karakteristik pemikiran-pemikiran masyarakat Jawa.

Jadi, filosofi Jawa isinya sarat akan pelajaran dan tuntunan hidup. Dengan adanya tuntunantuntunan hidup tersebut diharapkan masyarakat Jawa dapat mencapai tujuan hidupnya sehingga menjadi sempurna. Kesempurnaan hidup itu tidak saja dapat mencapai hal-hal yang sifatnya material tetapi juga mencapai hal-hal yang bersifat sosial dan spiritual. Tercermin pada tradisi-tradisi masyarakat Jawa yang sarat akan nilai religus, peduli sosial, peduli lingkungan, ramah-tamah, toleransi dan nilai-nilai luhur lainnya. Tidak hanya melalui tradisi, cerminan nilai-nilai juga dapat dilihat dari unen-unen yang dijadikan filosofi hidup masyarakat Jawa. Salah satunya adalah filosofi nrimo.

Filosofi nrimo diambil dari sesanti masyarakat Jawa yang populer dengan ungkapan nrimo ing pandum, makaryo ing nyoto. Sesanti ini terdiri dari dua kalimat yang tidak boleh dipisahkan, karena apabila dipisahkan akan membuat maknanya menjadi salah kaprah. Menurut Kamus Besar Bahasa Indonesia, salah kaprah berarti kesalahan yang umum sekali sehingga orang tidak merasakan sebagai kesalahan. Kesalahkaprahan pada sesanti ini adalah kalimat pertama yaitu nrimo ing pandum yang seringkali digembargemborkan, sedangkan kalimat makaryo ing nyoto jarang dipersandingkan. Hal ini mengakibatkan muncul stereotipe kepada masyarakat Jawa yang menganggap masyarakat Jawa itu etos kerjanya rendah berdasarkan kalimat nrimo ing pandum saja. Padahal maknanya lebih dalam dari itu. Secara bahasa, nrimo ing pandum berarti menerima pemberian, makaryo ing nyotoberarti bekerja secara nyata. Jadi, nrimo ing pandum, makaryo ing nyoto berarti masyarakat Jawa diharapkan dapat menerima pemberian dari Yang Maha Kuasa setelah bekerja keras secara nyata.

Berkenaan dengan filosofi Jawa dalam nrimo ing pandum, makaryo ing nyoto, Panggabean Hana dkk (2014, 129-130) 
menjabarkan bahwa nrimo merupakan salah satu standar budaya masyarakat Indonesia yang mampu digunakan sebagai strategi dalam menghadapi era global ini. Dalam bukunya yang berjudul Kearifan Lokal Keunggulan Global Cakrawala Baru di Era Globalisasi, Panggabean Hana dkk menjabarkan bahwa konsep nrimo yang berasal dari Filosofi Jawa merupakan satu konsep yang positif yang dicerminkan melalui sikap yang tenang, tidak gegabah, dan menerima apapun yang terjadi dalam hidup sehingga mampu memunculkan sikap positif lainnya yang berupa rasa toleransi. Menurut penulis, sikap nrimo juga menunjukkan sikap pengendalian diri yang kuat. Rasionalnya dengan memiliki sikap nrimo masyarakat Jawa berupaya untuk mengendalikan dirinya agar tidak bersikap secara berlebihan dengan marah, kecewa, rendah diri, dan putus asa, melainkan bersikap tenang dan berfokus untuk mencari penyelesaian masalah. Udasmoro Wening (1999, 43) menjelaskan bahwa pengendalian diri manusia Jawa yang utama adalah pengendalian terhadap nafsu dan angkara karena keduanya dianggap akan mengombang-ambingkan kehidupan manusia sehingga emosi meledak-ledak yang merupakan nafsu manusia yang amat dihindari oleh orang Jawa. Dengan demikian, unen-unen nrimo ing pandum, makaryo ing nyoto merupakan salah satu pegangan hidup masyarakat Jawa agar dapat menghadapi hidup dengan tenang dan tidak terbawa hawa nafsu.

Unen-unen nrimo ing pandum, makaryo ing nyoto ini data dilihat juga dalam tradisi-tradisi dalam masyarakat Jawa seperti tradisi yang dilakukan dalam masa kehamilan dan setelah kelahiran. Pada tanggal 20 September 2017, penulis melakukan wawancara kepada salah satu penduduk RT 8 RW 4 Desa Sidorejo, yaitu $\mathrm{Bu}$ Juariyah (72 tahun). Berdasarkan penuturan $\mathrm{Bu}$ Juariyah dapat diketahui tentang salah satu kearifan lokal yang ada di Desa Sidorejo yaitu prosesi pada masa kehamilan dan setelah melahirkan menurut adat Jawa. Menurut masyarakat Sidorejo, pada masa kehamilan dan setelah kelahiran ada tata kelakuan yang harus diperhatikan dan dilakukan oleh seseorang yang sedang hamil dan telah melahirkan. Tata kelakuan tersebut berupa mitos-mitos yang dipercayai dan prosesi kegiatan yang harus dilakukan selama hamil dan setelah melahirkan.

Ketika hamil, ada beberapa mitos yang masih dipercaya yang berupa keharusan dan larangan-larangan. Berikut ini beberapa larangan dan keharusan yang harus dilakukan oleh ibu hamil. (1) Ibu hamil dilarang makan sambil berdir apalagi sambil berjalan, dan dilarang makan di dalam kamar karena dipercaya akan berpengaruh pada proses kelahiran. Ketika larangan ini dilanggar maka dipercaya proses kelahiran seseorang tersebut menjadi sulit. (2) Ibu hamil harus selalu menjaga kebersihan, harus selalu membuang air kocahan (air bekas cuci piring), tidak boleh membiarkan air kocahan berhari-hari karena diyakini akan membuat anak yang lahir nantinya mengalami sakit mata (matanya seringkali mengeluarkan kotoran/belekan). (3) Suami dan keluarga ibu hamil dilarang untuk membunuh hewan-hewan. Hal ini dipercaya akan berimbas pada anak yang lahir. Misalnya, ketika suami ibu hamil mengolah udang (mbeteti dan sebagainya) maka diyakini akan membuat jari-jari anak yang lahir menjadi tidak sempurna (prethel). (4) Ibu hamil dilarang melilitkan handuk di leher karena diyakini akan membuat anak terlilit tali pusar ketika lahir. (5) Dan masih banyak lagi yang lainnya.

Adapun prosesi kegiatan yang harus dilakukan, ketika hamil ada 2 yaitu neloni dan mitoni. Adapun prosesi kegiatan yang harus dilakukan ketika bayi telah dilahirkan ada 6 kegiatan yaitu brokohan bayi, sepasar, selapan, neloni, mitoni dan setahunan. Kegiatan-kegiatan tersebut dilakukan sebagai bentuk usaha keluarga agar baik ibu hamil dan jabang bayi selamat selama proses kehamilan sampai kelahiran dan si jabang bayi tumbuh menjadi anak yang sehat dan baik.

Ketika sedang hamil, prosesi neloni dilaksanakan ketika usia kandungan jalan tiga bulan. Sedangkan prosesi mitoni dilaksankan ketika usia kandungan jalan 7 bulan. Yang wajib dilakukan ketika prosesi neloni dan mitoni adalah proses kenduren. Kenduren dilaksanakan dengan mengundang tetangga sekitar rumah untuk baca do'a dan pembagian makanan. Makanan yang wajib ada adalah Kulupan Sak Pepek e dan Trancam. Kulupan Sak Pepek e terdiri dari berbagai macam sayuran seperti daun singkong, daun kenikir, dan daun-daun lainnya selain daun kangkung dan daun papaya. Daun kangkung tidak boleh digunakan karena dipercaya membuat anak yang dikandung menjadi anak malas. Daun papaya tidak boleh digunakan karena membuat anak yang dikandung menjadi pahit (kurang dermawan). Yang baik adalah kacang panjang yang dibiarkan memanjang dengan alasan dapat 
mempermudah jalan untuk mencari rezeki. Trancam terdiri dari timun, kecambah, toro dan parutan kelapa diurap jadi satu. Dengan kulupan sak pepek e dan trancam sebagai makanan wajib diharapkan anak dalam kandungan dapat tumbuh menjadi anak yang seger (kuat dan harum). Prosesi mitoni hampir sama dengan prosesi neloni. Perbedaannya, dalam prosesi mitoni yang sering disebut dengan tingkepan, orang-orang yang datang kenduren disuguhi dengan rujak gobet.

Setelah anak lahir, maka dulure (ari-ari) harus dipendam di tanah. Apabila anaknya lakilaki maka harus dipendam di depan rumah pada sisi kanan, sedangkan apabila anaknya perempuan maka harus dipendam di depan rumah di sebelah kiri. Dan ketika Maghrib menjelang, maka pendaman ari-ari tersebut harus didamari (diberi penerangan). Hal ini dilakukan dengan tujuan agar anak terhindar dari segala gangguan baik penyakit maupun bala'.

Begitu anak lahir, keluarga di rumah menyiapkan prosesi brokohan bayi. Pada prosesi ini makanan yang wajib ada adalah jenang abang empat piring. Harus empat piring karena disesuaikan dengan unen-unen "jenang papat, limo jumeneng". Jenang abangnya empat dan kelimanya adalah si jabang bayi. Yang membedakan prosesi ini adalah yang hadir dalam kenduren adalah ibu-ibu.

Kemudian ketika bayi mengalami cuplak puser, prosesi sepasaran dilaksanakan. Setelah berusia 36 hari, dilaksanakan prosesi selapanan. Dilanjutkan dengan prosesi neloni ketika usia bayi jalan 3 bulan, prosesi mitoni ketika usia bayi jalan 7 bulan, dan prosesi setahunan ketika usia bayi jalan 12 bulan. Pelaksanaan kegiatan-kegiatan tersebut adalah sama, yaitu diadakan ritual kenduren. Berdasarkan kegiatan-kegiatan di atas dapat penulis simpulkan bahwa pada dasarnya kegiatan yang dilakukan selama masa kehamilan dan setalah kelahiran termasuk ke dalam adat selamatan.

Penulis berpendapat bahwa adat selamatan merupakan salah satu bentuk pengejahwantahan dari filosofi hidup nrimo ing pandumdalam kehidupan masyarakat Jawa. Nilai-nilai yang terkandung dalam kearifan lokal masyarakat Jawa pada masa kehamilan dan setelah kelahiran adalah nilai religius, nilai kerja keras, nilai persatuan, nilai kreatif dan nilai peduli sosial. Nilai religius merupakan sikap dan perilaku yang patuh dalam melaksanakan ajaran agama yang dianutnya. Kaitan kearifan lokal tersebut dengan nilai religiusitas adalah kemauan melaksanakan kaidahkaidah dari agama. Lebih lanjut pelaksanakan kearifan lokal ini juga menunjukkan sebuah rasa syukur atas rezeki yang telah diberikan Tuhan Yang Maha Kuasa. Dari tradisi-tradisi di atas tercermin sebagai wujud nrimo akan karunia Tuhan Yang Maha Kuasa yaitu anak, masyarakat Jawa menyelenggarakan ritual-ritual sebagai rasa kesyukurannya dan sebagai do'a agar anak dapat tumbuh menjadi anak yang bermanfaat, sebagai wujud makaryo.

Namun, ada beberapa pemaknaan yang salah dari konsep nrimosalah satunya adalah mengartikan sebagai sifat pasrah, mudah menyerah dan enggan berubah terhadap suatu keadaan yang ada (Hana Panggabean, 2014: 132133). Hal ini mengakibatkan masyarakat yang berdaya juang rendah, mengambinghitamkan filosofi nrimo ing pandum agar sifat mudah menyerahnya dimaklumi. Seharusnya nrimo dipahami sebagai kekuatan untuk tetap melangkah karena dilandasi niatan "Tuhan memiliki rencana yang lebih baik dikemudian hari”. Kesalahan dalam memaknai ini merupakan akibat dari pemisahan dua kalimat yang sebenarnya merupakan satu kesatuan. Maka dari itu, agar tidak menjadi lebih salah kaprah, perlu dilakukan kajian ilmiah terhadap filosofi Jawa yang sesungguhnya untuk kemudian dipublikasikan.

\section{FILOSOFI NRIMO DITINJAU DARI SILA KETUHANAN YANG MAHA ESA}

Filosofi Jawa nrimo memiliki makna yang lebih jika ditinjau dari Nilai Ketuhanan Yang Maha Esa. Seperti kita ketahui filosofi Jawa merupakan nilai dasar yang dipegang teguh oleh masyarakat Jawa, nilai-nilai ini sudah ada bahkan jauh sebelum agama seperti Islam dan Kristen masuk ke Indonesia. Dengan kata lain, filosofi hidup masyarakat Jawa didasarkan pada nilai-nilai Ketuhanan nenek moyang bangsa Indonesia yang didasarkan pada kepercayaan yang dianut pada masa itu. Dan ketika peradaban semakin bertambah maju dengan masuknya agama Hindu, Budha, Kristen, Islam sampai dengan Kong Hu Chu, nilai-nilai Ketuhanan didasarkan pada keyakinan agamanya masingmasing. Begitu pula dengan filosofi-filosofi hidup masyarakat Jawa yang kemudian disesuaikan dengan ajaran agama yang berkembang dalam 
masyarakat Jawa. Jadi, dapat dikatakan bahwa nilai-nilai Ketuhanan masyarakat Indonesia didasarkan pada kepercayaan, keyakinan serta agama yang dianut oleh masyarakat Indonesia yang kemudian dikristalkan menjadi Sila Pertama Pancasila, yaitu Ketuhanan Yang Maha Esa yang menunjukkan kereligiusitasan Bangsa Indonesia. Sehingga, dalam mengkaji filosofi hidup masyarakat Indonesia dapat pula ditelaah melalui ajaran-ajaran agama yang dianut masyarakat Indonesia. Pada tulisan ini, penulis tertarik untuk mengkaji filosofi hidup nrimo ing pandum, makaryo ing nyoto sebagai perwujudan nilai Ketuhanan dalam kehidupan masyarakat Jawa ditinjau dari ajaran Islam.

Ditinjau dari ajaran Islam, filosofi hidup nrimo ing pandum, makaryo ing nyoto merupakan istilah lain dari ikhtiar dan tawakkal. Dalam ajaran Islam, ikhtiar dan tawakkal adalah satu kesatuan yang tidak boleh dipisahkan. Ikhtiar merupakan bentuk usaha dari manusia untuk mencapai sesuatu. Sedangkan tawakkal merupakan bentuk penyerahan diri diri atas kerja keras yang telah dilakukan. Dengan tawakkal inilah kemudian muncul istilah nrimo.Dalam sebuah riwayat hadist dijelaskan, "Jika kalian benar-benar berserah diri kepada Allah dengan sungguh-sungguh, niscaya Allah akan memberi rezeki pada kalian sebagaimana Allah memberi rizki pada burung yang pergi (dalam keadaan lapar) untuk mencari makan ketika pagi dan kembali lagi ke sarang (dalam keadaan kenyang) pada waktu sore hari (HR. Ibnu Majah, Nomor 4164). Berdasarkan riwayat tersebut, umat Islam diajak untuk bekerja keras dalam mencari nafkah sebagaimana burung yang setiap hari menjelajah langit untuk mencari penghidupan, adapun hasilny (banyak sedikitnya nafkah) diserahkan sepenuhnya kepada Tuhan.Filosofi hidup nrimo sejalan dengan kegiatanbertawakkal sedangkan ikhtiar senada dengan semangat makaryo ing nyoto untuk menghadapi segala sesuatu dengan cerdas dan tidak sekedar berdiam diri.

Dari penjelasan di atas dapat diambil kesimpulan bahwa konsepnrima sangat berhubungan erat dengan nilai Ketuhanan. Nilai Ketuhanan sebagai puncak Hirarki Piramida Pancasila memiliki peran yang sentral dalam membentuk karakter manusia Indonesia. Sehingga dapat juga dikatakan bahwa filosofi nrimo juga merupakan filosofi hidup bagi masyarakat Indonesia yang berKetuhanan Yang Maha Esa. Dengan adanya kearifan lokal berupa filosofi Jawa ini bisa mempertegas karakter manusia Indonesia dengan catatan filosofi-filosofi kehidupan yang berkembang dalam masyarakat tetap dijaga dan diuri-uri. Mengingat filosofi hidup masyarakat Jawa pada khususnya dan masyarakat Indonesia pada umumnya sarat akan nilai-nilai Ketuhanan perlu pemahaman lebih bahwa masyarakat Indonesia bukanlah masyarakat yang pandai beranganangan tanpa ada usaha. Namun, lebih dari itu dengan berpedoman pada nilai-nilai Ketuhanan menjadikan bangsa Indonesia menjadi bangsa yang mengedepankan nilai-nilai kekeluargaan, ketenangan, kesabaran, dan selalu mempertimbangkan segala sesuatu dengan baik dan bijak. Sebagaimana yang disampaikan oleh T.B Simatupang (Tengku Irmayanti, 2014) yakni, "Sejarah membuktikan bahwa agama tidak saja merupakan sesuatu yang terdekat dan terpokok dalam memenuhi kebutuhan manusia, tetapi juga sebagai sumber inspirasi dan motivasi dalam pengembangan berbagai ilmu pengetahuan demi meningkatkan kualitas manusia dan masyarakat". Jadi, sudah seharusnya bahwa filosofi-filosofi hidup bangsa dikaji secara ilmiah dan dimaknai sesuai dengan yang diharapkan oleh nenek moyang bangsa Indonesia, yaitu dibuat untuk dijadikan pedoman dalam mencapai kesempurnaan hidup yaitu kehidupan yang bertuhan, berperikemanusiaan, menjunjug tinggi persatuan, berkerakyatan demi mencapai kesejahteraan dan keadilan. Filosofi-filosofi hidup bangsa yang merupakan suatu hal yang ideal, tentu saja tidak semua masyarakat mampu untuk mengamalkannya. Maka dari itu, perlu dibuat rencana terstruktur untuk menghidup-hidupkan filosofi hidup bangsa. Salah satu langkah strategis yang dapat dilakukan untuk melestarikannya adalah melalui dunia pendidikan, yaitu khususnya Pendidikan Karakter yang Berbasis Kearifan Lokal.

\section{SIMPULAN}

Setiap masyarakat Indonesia memiliki kearifan lokal sebagai cerminan dari nilai dan karakter yang dianut oleh masyarakat itu. Pada masyarakat Jawa khususnya, kearifan lokal yang berupa filosofi hidup banyak sekali ragamnya. Salah satu filosofi hidup yang diyakini oleh mayarakat Jawa adalah nrimo. Nrimo, diyakini sebagai karakter masyarakat Jawa dalam 
menjalani hidup. Masyarakat Jawa yakin bahwa setelah bekerja keras maka hal yang dilakukan adalah nrimo apapun hasil yang diberikan oleh Tuhan dan bersyukur atas berkah yang telah diberikan oleh Tuhan atas kerja keras yang telah dilakukan. Konsep filosofi Jawa nrimo mengandung nilai-nilai luhur bangsa seperti nilai

\section{DAFTAR RUJUKAN}

Badan Pusat Statistik. 2011. Kewarganegaraan, Suku Bangsa, Agama dan Bahasa Sehari-hari Penduduk Indonesia Hasil Sensus Penduduk 2010. ISBN 9789790644175.

Badan Pusat Statistik. Jumlah dan Distribusi Penduduk Menurut Hasil Sensus Penduduk Tahun 2010. (Artikel online, https://www.bps.go.id, diakses pada tanggal 10 Desember 2017)

Bayuadhy, Gesta. 2015. Tradisi-Tradisi Adiluhung Para Leluhur Jawa. Yogyakarta: Dipta

CNN GoStaff. 2012. Denmark ousted from top 100: World's new happiest country is ... (Artikel online, http://travel.cnn.com, diakses pada tanggal 10 Desember 2017)

Dahliani. 2015. Local Wisdom In Built Environment In Globalization Era. International Journal of Education and Research Vol. 3 No. 6 June 2015 religius, kerja keras, peduli lingkungan dan lain sebagainya. Filosofi ini sangat sesuai dengan nilai Ketuhanan Yang Maha Esa. Untuk itu, sangat perlu dilakukan usaha untuk melestarikan filosofi hidup ini. Strateginya adalah melalui Pendidikan Karakter yang Berbasis Kearifan Lokal.

Irmayanti, Tengku. Religiositas dan Motivasi Kerja, online, http://www.repository. uinjkt.ac.id/dspace/bitstream/ 123456789/36462/1/IIN\%20 SUMAEROH\%20-\%20FUF.pdf

Mungmachon, Roikhwanphut. 2012. Knowledge and Local Wisdom: Community Treasure. International Journal of Humanities and Social Science Vol. 2 No. 13; Juli 2012

Panggabean, Hana, dkk. 2014. Kearifan Lokal Keunggulan Global Cakrawala Baru di Era Globalisasi. Jakarta: PT Elex Media Komputindo

Udasmoro, Wening. 1999. Memahami Karakteristik unconscious Filosofi Jawa Melalui Tokoh Wayang Bima. Jurnal Humaniora No. 12 September-Desember 1999, halaman 43

Wibawa, Sutrisna. 2013. Filsafat Jawa dalam Serat Wedhatama. Jurnal IKADBUDI Volume 2 Desember 2013 